\title{
ANÁlise da FundamentaÇão JuSFilosófica para Atribuição de Direitos Sociais no Caso Concreto Via Procedimento Judicial
}

\section{Ricardo Libel Waldman*}

\section{INTRODUÇ̃̃̃O}

Este artigo visa analisar a possibilidade de exigência de direito social mediante ação judicial. Para tanto se examinará um caso concreto para, indutivamente, determinar a possibilidade jurídica de tal demanda. Será utilizada para esta análise uma teoria liberal, no sentido da tradição norte-americana, a tespeito da justiça e dos direitos subjetivos, bem como o aquilo que podemos chamar de ponto de vista do bem comum sobre o mesmo problema.

Pois bem, o caso concreto a ser analisado se refere ao pedido, por um menor que tinha uma doença rara e muito séria, para a qual existia apenas um tratamento experimental dispoñível, no sentido de receber recursos do Estado para custear este procedimento médico. Tal procedimento estava sendo desenvolvido nos Estados Unidos e custaria US $\$ 163.000,00$ (cento e sessenta e três mil dólares). O Tribunal de Justiça do Estado de Santa Catarina, no Agravo de Instrumento $0^{\circ}$ 97000411-3, deferiu o pedido sem oitiva do Estado (AMARAL: 2000).

A utilização de uma teoria liberal justifica-se na medida que se percebe a base fundamentalmente individualista de uma decisão como esta, que visa principalmente a efetivação de direito subjetivo constitucionalmente garantido.

A análise do ponto de vista do bem comum, por ou tro lado, se justifica a medida em que a partir de um ponto de vista oposto ao liberal, leva à mesma conclusão: nem todos os direitos sociais garantidos na constituição podem ser efetivados por procedimentos judiciais individuais quando não estiverem determinados em nivel infra-constitucional.

* O autor é Mestre en Direito pela UFRGS, doutorando em direito na mesma instituição e professor da área de propedêutica jurídica na PUCRS, UNIRITTER, ULBRA/TORRES e IE SÃO JUDAS TADEU. 
Este artigo será divido em dois capitulos, que se subdividem em duas seções: no primeiro discutir -se-á o ponto de vista liberal, em uma seção teórica e outra de análise do caso, no segundo, o tópico de trabalho será o ponto de vista do bem comum, também com uma seção teótica e outra de análise do caso.

Passemos, então, a discussão de cada um deles, tentando buscar indícios para a solução de um problema da mais alta complexidade e que muitas vezes chega ao juiz como sendo uma situação de vida ou morte.

\section{I - LIBERALISMO'}

\section{A. Teoria}

Nesta seção serão descritas as principais teses liberais sobre as relações sociais e juridicas entre os individuos. É claro que existem formas diferentes de liberalismo, mas aqui a linha de pensamento mais importante é a do igualitarismo. Outra versão do liberalismo, o libertarismo de Nozick (NEDEL: 2000, p.89-96), seria contrário ao direito brasileiro, pois defende um Estado que só garante segurança pública e nossa constituição exige muito mais.

$\mathrm{Na}$ doutrina Liberal, o bem de cada individuo é independente do bem dos outros (BARZOTTO:2002), no sentido de que o bem de outra pessoa interessa ao indivíduo apenas quando isso the (a ele individuo) trouxer algum benefício. Rawls, por exemplo afirma que os seus princípios de justiça "são os princípios que pessoas livres e racionais preocupadas em favorecer seus próprios interesses aceitariam em uma posição inicial de igualdade como definidores de sua associação" (RAWLS: 1994, p. 11 - tradução livre, grifo nosso).

Sendo assim, dizer que alguém tem um direito, do ponto de vista liberal, informa que um dado estado de coisas, que favorece este alguém, deve ser protegido ou efetivado, mesmo que a socicdade como um todo fique pior (DWORKIN:1991, p.22).

Os direitos que alguém tem são poderes a serem exercidos contra os outros. Direitos entram em cena quando as pessoas sentem que não podem contar umas com as outras. $O$ caso ora discutido é túpico, o autor/agravante sabendo que o Estado não the garantiria por vontade própria o seu direito, invoca este em juízo.

\section{B. Análise do caso}

É tendo isto em mente, que os juizes deram provimento ao agravo; existe um direito subjetivo a saúde, garantido pela constituição a todos os cidadãos. Logo, não importa o quanto custe, este direito deve ser protegido. A ação judicial ganha ainda mais importância quando o Estado normalmente não cumpre seus deveres, adquirido esta caráter de pressão

1 As referênciạ bibliográficas serão indicadas pelo sistema autor-data, as explicaçôes adicionais consideradas necessárias pelo autor serão feitas por nota de rodapé. 
politica contta os órgãos competentes - se os governantes quiserem evitar um governo de juizes, terão que agir de acordo com a constituição.

Isto parece estar de acordo com a visão liberal. Mas, na verdade, não está.

A constinuição determina que o direito à saúde se gatante mediante políticas públicas (CF art. 196), e não através de todo tratamento e a todo custo.

Além disso, existe uma diferença entre direitos concretos e abstratos (DWORKIN: 1991, p. 93). O último não tem um peso determinado no caso concreto, o segundo tem. Logo, apesar de a constituição garantir o direito a saúde, esse é um direito abstrato que só deve ser garantido se for um direito concreto no caso.

A determinação a respeito da existência ou não de um direito concreto neste caso deve levar em consideração os direitos de outros brasileiros, que podem precisar dos mesmos tecursos de o autor/agravante. É uma questão de "Empatia iluminada [que reconheçamos] o outro com um auto-iniciador de ação mesmo em um sentido muito limitado, pois nós não poderíamos entender a nós mesmos sem esta capacidade. [A empatia iluminada] também iria requerer o reconlecimento do outro como capaz de sofrer como nós, através de frustração, dor física, etc." (GUEST: 2001, p. 14-tradução nossa).

Então, todos nós devemos reconhecet o diteito de auto-deteminação dos outros, assim como nós queremos este direito. É inaceitável que uma pessoa possa demandar que o judiciário leve em consideração apenas seu direito, quando todos os outros tem tanto ditcito quanto ela.

Um argumento processual poderia ser aduzido também: este caso se assemelha aos de falência (e no caso do Estado Brasileiro a analogia é quase identidade), quando todos os credores são chamados a receber pelo menos parte do seu crédito. $O$ procedimento falimentar é assim porque todos os credores têm direitos referentes a uma mesma quantidade de recursos e não existem recursos suficientes para pagar a todos. Recursos para a saúde no Brasil são escassos, então todos os credores devem ser parte do processo que decide que parcela pertence a quem.

Alguém poderia argumentar que se outros precisassem dos recursos tanto quanto o autor/agravante, deveriam ter processado o Estado também. Mas este não é o ponto. $O$ ponto é que o dinheiro que ele recebeu vai ser retirado de algum outro lugar. E algumas crianças vão deixar de receber lanche na escola, ou alguma adolescente pobte vai deixar de receber pillulas anti-concepcionais, ou alguém com um problema nos tins vai deixar de receber tratamento de hemodiálise. Estas pessoas devem ser ouvidas quando uma decisão é tomada a respeito de onde o Estado gastará seus recursos.

Por fim, uma última objeção poderia ser feita. Se o direito à saúde é mesmo um direito, deve existir uma maneira de garanti-los além da discussão politica nas eleições e pressões durante o exercício do mandato pelo eleito. De outro modo, a proteção constitucional deste direito não significará nada. 
A ação civil pública e a ação popular - além do controle concentrado de constitucionalidade - servem a este propósito, pois não existe direito mais difuso do que o de exigir o cumprimento da constituição e das leis. Os procedimentos da ação popular e ação civil pública permitem demandar contra o Estado, ou quem quer que seja, requerendo que este dê a justa prioridade para o sistema de saúde, que o governo respeite as leis orçamentátias que determinem investimentos na saúde pública, etc. A proteção de um direito à saúde dessa maneira permitiria tanto a efetiva garantia do direito quanto o respeito pela humanidade em todos os cidadãos, dado que qualquer recurso gasto em razão destes procedimentos será usado de um modo que todos possam ser beneficiados. O direito determina a criação de funcios para repatar os danos, no caso de ação civil pública (art. 13, Lei 7347/85), ou, no caso de ação popular, o pagamento aos cofres públicos das perdas e danos causados (arr. 11, Lei $4747 / 85)$. Deste modo, um indivíduo pode argüir no judiciário um dano a direito que não é apenas seu e, além disso, fazer com que todos os titulares deste direito sejam beneficiados com este único procedimento judicial.

A primeira vista este tipo de procedimento vai contra os postulados do liberalismo, mas, na verdade, se fundamentaria no respeito que devemos aos nossos semelhantes enquanto tais. Se não somos obrigados a auxiliar o próximo, uma vez que optamos por isso, é nosso dever fazê-lo da melhor forma possível, pois é isso que nós gostariamos que os outros fizessem por nós.

\section{II - PONTO DE VISTA DO BEM COMUM}

\section{A. Teoria}

O ponto de vista do bem comum é fortemente baseado na teoria do direito natural de John Finnis, (1999, passim) e naquilo que pode ser chamada de "tradição clássica", como oposta à "tradição liberal" ou "moderna"2. A importância desse ponto de vista é que ele traz de volta aspectos valiosos da "tradição clássica", como as noções de bem comum e realização pessoal, sem abandonar as conquistas que o liberalismo alcançou ao debate político, como a noção de direitos subjetivos entendidos como partes fundamentais das discussões políticas e jurídicas. Finnis acredita que "a moderna linguagem dos direitos", por exemplo, pode oferecer um "instrumento potencialmente preciso para determinar as exigências da justiçą" (1999, p. 210).

2 Usanse estas expressões no sentido de Alasdair Macintyre em suas obras After virtue. 2nd. Edition. Notre Dame: University of Notre Dame Press, 1964, e Justiça de quem? Qual Racionalidade? São Paulo: Loyola, 2002, ou seja, tradição clássica, aquela nascida na Grécia Antiga e que tem seus maiores expoentes en Aristóteles e Tomás de Aquino (Justiça..., p. 21) e a tradição moderna, que surge na Europa, ao redor do séc. XVII e que tem em Kant seu melhor expoente (ustiça...,p. 359). 
Este ponto de vista afirma que uma parte importante do bem pessoal é o bem comum (FINNIS:1999, p. 154). Alguém só pode dizer que é feliz ou realizado (que tem "eudaimonia" $)$, quando todos os outros estão em condições de se realizatem também. Esse estado de coisas, onde todos podem fazer o melhor de si mesmos é o bem comum, e o bem comum é o objetivo da associação política, de viver em comunidade.

O direito positivo é o modo de preservar este estado de coisas, naquilo que a conduta individual é relativamente influente no bem dos outros, nesse sentido é possível falar em bem público (FINNIS:1998, p123) ou bem comum politico (SANTIAGO:2001, p.41-44). $O$ direito é justo quando promove o bem comum. Isso pode ser feito indiretamente, através do bem particular de una pessoa (justiça comutativa e distributiva-AQUINO:1956, Q. 58, art. $7^{\circ}$ ) ou diretamente (justiça legal- AQUINO:1956, Q. 58, art. $7^{\circ}$ )

O tespeito à igualdade é, normalmente, a melhor maneira de evitar desrespeito pela dignidade pessoal (GUEST:2002, pp.7-8). No entanto, se ser uma pessoa como as outras é o que nos dá direito à igualdade, o que nos faz ser capaz de ter direitos é o fato de nós sermos humanos. E a realização da vida humana é a única razão para toda a ação humana, e não a igualdade. É por isso que se pode dizer que "a noção central do conceito de justiça social [legal] é a noção de ordem, entendida como a disposição das coisas em vista do bem comum" (BARZOTTO:2003, p.185), ou seja, das condições que permitem o desenvolvimento da pessoa humana, e "a noção central do conceito de justiça particular é a noção de igualdade" (idem, ibidem). Ou seja, em alguns momentos realiza-se o bem comum pela ordem, diretamente, outras vezes, indiretamente, pela igualdade.

Algumas características do bem comum podem ser indicadas (SANTIAGO:2001, 51-60): é necessário, orientado à pessoa, prático, difuso, limitado, ético, cultural, histórico, universal, espontâneo, gradual, jurídico, conflitivo, subsidiário e concreto. Destas, veja-se algumas características especificamente:

1) O ben comum é necessário, pois é a razão de ser da associação política.

2) É orientado à pessoa porque consiste em propiciar a realização pessoal. Essa realização pessoal tem de ser diferente de algum bem coletivo, apesar de dever incluir o bem das outras pessoas. Isto pois, a pessoa humana, assim como não pode ser reduzida a parte de um todo maior, é também abertà comunicação com outros seres racionais e é nesta vida em comum com outros seres racionais, que ela se realiza (BARZOTTO:2003, p. 180).

3 De acordo com Aristótales ofim úkimo da vida humana é eudaimoniá, que é normalmente traduzida por felicidade, e que implica na existência humana en toda a sua plenitude. ARYSTÓTELES. Ética a Nicômaco. Edicion bilíngue y traducción de Maria Araújo e Julian Maria. Madrid: Centro de Estudios Constitucionales, 1994, 1095a. 
3) É cultural, pois sua realização é feita através da ação criativa. Podem existir diferentes, mas igualmente corretas, formas de obter o bem comum, de modo que diferentes culturas podem dar soluções próprias, para seus próprios problemas.

4) É histórico, porque condições históricåss diferentes requerem diferentes modos de perseguir o bem comum.

5) É jurídico, pois tem de ser determinado por decisões politicas, que tornem os requerimentos do ben comum em obrigações jurídicas.

6) É conflitivo, pois as pessoas têm problemas e interesses diferentes e todos nós tendemos a tentar resolver os nossos problemas primeiro. Assim, a realização do bem comum deve ser feita attavés da escolha de algumas opções e não outras, gerando sempre algum conflito.

Seguindo esta linha de raciocínio, direitos subjetivos são aspectos do bem comum, a partir do ponto de vista individual (FINNIS:1999, 210). Ninguém pode ter um direito quando é claro que todos os outros ficarão irrazoavelmente pior, mas as pessoas têm de ter alguns direitos se o bem comum é para ser atingido.

É evidente que as liberdades de expressão, de religião, de associação, devem ser garantidas. A história nos mostra isso. Também é claro que, apesar da liberdade ser necessária, não pode ser absoluta. Todos que atingem determinada idade devem ter o direito de votar e ser votado. Saúde, educação, moradia e trabalho, também são aspectos do bem comum.

Mas, como o bem comum é conflitivo, histórico e cultural, toda a comunidade deve tomar parte na sua determinação, e na determinação dos direitos necessários para a sua realização. Isso, é claro, com respeito a direitos como os referidos acima, que, a experiência já mostrou, são essenciais para o bem comum.

\section{B. Análise do caso}

No caso em exame, não há decisão política sobre o direito do autor de receber o tratamento que ele requer. A Constituição garante o direito à saúde, mas a palavra direito, propriamente entendida, significa que um estado de coisas deve ser protegido na medida em que é um aspecto do bem comum. O ben comum é determinado, entre outras formas, pela lei orçamentária. Se a comunidade democraticamente escolheu beneficiar bebês recém-nascidos, mães solteiras, etc. e não pessoas afetadas por doenças raras, apesar de essa ter sido uma escolha trágica, o juiz não pode decidir diferentemente, aindã mais quando o tratamento ainda não se provou eficiente e, alén disso, é muito caro. O direito constitucionalmente previsto deve ser interpretado como um direito abstrato, sem determinação do seu peso, com relação a outros diteitos no caso concreto. Se houvesse determinação constitucional específica, ou determinação infra-constitucional, teriamos um direito concreto, com peso definido no caso concreto. Mas, como efetivar direitos abstratos como esses?

Como foi dito antes, o direito brasilciro tem um modo de lidar com a omissão do governo na efetivação de direitos a práticas de políticas públicas. A ação civil pública e a ação 
popular - além do controle concentrado de constitucionalidade - servem a este propósito, pois não existe direito mais difuso do que o de exigit o cumptimento da constituição e das leis.

E não há problema em autorizar uma pessoa ou grupo de pessoas a tomar conta de problemas que causam danos diretos a outras: o bem de uma pessoa depende do bem das outras.

Assim, não apenas porque é devido a um igual, mas porque é algo que é devido por cada um de nós, a si mesmo enquanto pessoa buscando a realização pessoal, que uma pessoa pode ser um guardião confiável dos direitos dos outros. Essa pode ser uma defesa mais forte deste tipo de procedimento do que o liberalismo pode oferecer.

A diferença é que o liberalismo afirma que urna pessoa deve tomar conta do bem estar das outras porque ela iria querer que as outras, pelo menos quando existe o compromisso nesse sentido, tomassem conta dela também. O ponto de vista do bem comum, argumenta que uma pessoa quer tomar conta do bem estar dos outros, porque ela só pode estar bem quando os outros estiverem bem também ${ }^{4}$. E isso faz toda a diferença na motivação para fazer o melhor trabalho possível na defesa do bem-estar das outras pessoas.

\section{CONCLUSÃO}

A atribuição de direitos sociais em abstrato na constituição não significa, necessariamente, que existan direitos concretos a determinado tipo de prestação para um certo indivíduo, como por exemplo, um tratamento de saúde. Sobre isso, pontos de vista (liberal e do bem comum) com fundamentos muito diferentes concordam.

* Esta característica aparece ern ARISTÓLETELES - Política.

Lisboa: Vega, 1998. Entre 1280 a e 1281 a, ele aponta diversos exemplos para demonstrar que a comunidade política não pode ter por fim apenas evitar que os homens causem mal uns aos outros, caso contrário, como ele diz "os Etruscos e os Cartagineses e os demais povos que têrn tratados comerciais entre si, pertenceriam a uma única cidade. É verdade que tais povos têm acordos relativos à importação e exportação; comprometem-se a respeitar uma conduta justa e tratados de defesa mútua" (linhas 36 e ss.), mas característica tipica da comunidade política é a busca da "vida boa e a garantia de uma existência perfeita e autônoma." Esta busca se tealiza através de instituiçōes que "são obtas da amizade (...)" $1280 \mathrm{~b}$ linha 38. A comunidade política, portanto, pressupóe que o bem de cada uma das partes conte para o bem dos outros, de um modo que na elabotação do plano de vida de cada un deve haver uma flexibilidade no sentido de incluir o bem dos outros po: si mesmos e de maneira independente dos projetos individuais que cada um possa ter, como scus (FINNIS - Natural. pp.142-143) - embora fique claro que, entre anigos, muitos fins (bens) sào comuns - $\mathrm{e}$ isto deve ser reciproco e reconhecido por todas as partes (Sobre reciprocidade a amizade: ARISTÓTELES. Ética a Nicômaco. Edicion bilingue y traducción de Maria Araújo e Julian Mária. Madrid: Centro de Estudios Constitucionales, 1994.1156a). 
A determinação de quais direitos sociais abstratos conferem direitos concretos depende dos fundamentos para a existência destes direitos e da interpretação segundo estes fundamentos das normas juridicas.

Quando não houver direito social concreto a uma prestação individualizadă, a proteção dos direitos sociais não se inviabiliza, pois ainda há o direito social concreto de exigir do Estado a realização de politicas públicas, nos termos da constituição e da legislação infraconstitucional, através da ação popular e da ação civil pública.

\section{REFERÊNCIAS BIBLIOGRÁFICAS}

AMARAL, Gustavo. Direito, escassez e escolha. Rio de Janeiro: Renovar, 2001.

AQUINO, Santo Tomás de. Summa Theologica - Tomo VIII: Tratado de la Justicia. Edición bilíngue (latim-espanhol). Traducción, introducciones e apêndices: Fr. Teofilo Urdanoz, O.P. Madrid: BAC, 1956.

ARISTÓTELES. Ética a Nicômaco. Edicion bilíngue y traducción de Maria Araújo y Julian Maria. Madrid: Centro de Estudios Constitucionales, 1994. Política: Edição bilíngüe. Lisboa: Vega, 1998.

BARZOTTO, Luis Fernando. A democracia na constituição. São Leopoldo: Unisinos, 2003

FINNIS, John M. Aquinas. Oxford: Clatendon, 1998. . Natural Law and Natural Rights. Oxford: Clarendon, 1999.

GUEST, Stephen. Why is the law just? Downloaded from http: // www.ucl.uk/ $\sim$ uctlsfd/papers/index.html in $07 / 29 / 2002$.

MACINTYRE, Alasdair. After virtue. 2nd. Edition. Notre Dame: University of Notre dame Press, 1984.

2002. Justiça de quem? Qual Racionalidade? São Paulo: Loyola,

SANTIAGO, Alfonso. Bien común y derecho constitucional: el personalismo solidario como techo idcológico del sistema político argentino. Buenos Aires, 2001. 